\title{
New concepts regarding cerebral vasospasm: glial-centric mechanisms
}

\section{Nouveaux concepts concernant le vasospasme cérébral: des mécanismes centrés sur la glie}

\author{
W. Alan C. Mutch, MD
}

Received: 5 October 2009/Accepted: 12 January 2010/Published online: 4 February 2010

(c) Canadian Anesthesiologists' Society 2010

\begin{abstract}
Purpose Poor outcome in patients with cerebral vasospasm following subarachnoid hemorrhage remains a serious clinical problem. The current management with focus on the cerebrovascular constriction accounts for the use of "triple- $H$ " therapy (hypertension, hypervolemia, and hemodilution) to enhance cerebral blood flow through constricted vessels. Recent work suggests that spreading depression (a stereotypical response of cerebral cortical tissue to noxious stimuli with subsequent oligemic blood flow) occurs in patients with cerebral vasospasm. A narrative review was conducted to examine the relationship between spreading depression and subarachnoid hemorrhage and to identify the anesthetic effects on the propagation of spreading depression.

Principal findings Following review of the literature, an underlying mechanism is advanced that cerebral vasospasm is not primarily a problem of the cerebral vasculature but a consequence of glial cell dysfunction following spreading depression - a glial-centric cause for vasospasm. Such a mechanism for vasospasm becomes manifest when spreading depression waves transition to peri-infarct depolarization waves - with protracted ischemic blood flow in compromised tissue. The extracellular microenvironment with high potassium and low nitric oxide tension can account for conducting vessel narrowing.

Conclusions The implication for clinical management is discussed supposing glial cell dysfunction is an underlying mechanism responsible for the vascular spasm.
\end{abstract}

\section{W. A. C. Mutch, MD ( $\square)$}

Department of Anesthesia, Anesthesia Research Laboratory, University of Manitoba, A504 Chown Building, 744 Bannatyne Avenue, Winnipeg, MB R3C 0W2, Canada

e-mail: amutch@cc.umanitoba.ca

\section{Résumé}

Objectif Les mauvais pronostics chez les patients manifestant un vasospasme cérébral à la suite d'une hémorragie sous-arachnoïlienne demeurent un problème clinique majeur. La prise en charge actuelle se concentre sur la constriction vasculaire cérébrale, ce qui explique le recours au traitement dit des "trois $H$ » (hypertension, hypervolémie et hémodilution) dans le but d'ameliorer le débit sanguin cérébral dans les vaisseaux contractés. Des recherches récentes suggèrent qu'une dépression propagée (une réaction typique du tissu cortical cérébral aux stimuli nociceptifs, laquelle est suivie d'un débit sanguin réduit) survient chez les patients manifestant un vasospasme cérébral. Un compte-rendu narratif a été entrepris afin d'examiner la relation entre la dépression propagée et l'hémorragie sous-arachnoïienne ainsi que d'identifier les effets des anesthésiques sur la propagation de la dépression propagée.

Constatations principales Après avoir passé en revue la littérature sur le sujet, l'hypothèse d'un mécanisme sous-jacent est avancée, selon laquelle le vasospasme cérébral n'est pas un problème principalement lié à la vasculature cérébrale mais plutôt la conséquence d'un dysfonctionnement des cellules gliales après une dépression propagée - en d'autres mots, le vasospasme est causé principalement au niveau glial. Ce mécanisme qui provoque le vasospasme est manifeste lorsque les vagues de dépression propagée se changent en vagues de dépolarisation autour de l'infarctus, soit avec un débit sanguin ischémique prolongé dans les tissus compromis. Le micro-environnement extracellulaire, qui comporte des quantités elevées de potassium et basses d'oxyde nitrique, peut expliquer le rétrécissement des vaisseaux conducteurs.

Conclusion Les implications de ces découvertes dans la prise en charge clinique sont discutées en partant de 
l'hypothèse que le dysfonctionnement des cellules gliales est l'un des mécanismes sous-jacents responsables du spasme vasculaire.

Cerebral vasospasm (marked narrowing of conducting arteries and parenchymal arterioles) following subarachnoid hemorrhage (SAH) remains a major cause of morbidity and mortality. ${ }^{1-4}$ Vasospasm may account for up to one-third of infarctions or deaths following a cerebral bleed - estimated to affect up to 1.2 million patients worldwide per annum. ${ }^{5}$ Radiologically, from $60-70 \%$ of patients with SAH manifest with vasospasm, which is detectable for up to two weeks following the ictus. Up to one-half of these patients will experience clinical signs of cerebral ischemia. The onset is commonly within three to 12 days after the initial hemorrhage.

\section{Historical mechanisms}

Historically, vasospasm following SAH has been deemed to be a problem of the cerebral vasculature (Figure 1). Blood in the subarachnoid space bathing cerebral vessels in some manner causes vasoconstriction. Various mediators of constriction have been advanced: irritation from hemoglobin or breakdown products of hemoglobin, including bilirubin oxidation products (BOXes) and other reactive oxygen species; binding of nitric oxide (NO) by hemoglobin; production of endothelin-1 by damaged endothelium; generation of 20-hydroxyeicosatetraeonic acid (20-HETE) from arachidonic acid; infiltration of the vessel wall by inflammatory cells resulting in vessel narrowing; and manipulation of cerebral vessels during surgical intervention to clip the ruptured aneurysm. ${ }^{5-8}$

The premise of "triple-H" therapy (hypertension, hypervolemia, and hemodilution), which remains a cornerstone of management of intractable cerebral vasospasm, is that ischemia will be relieved by overpowering vessel vasoconstriction by a greater perfusion pressure. ${ }^{2,9,10}$ Indeed, this combination therapy can be therapeutic in a significant proportion of patients but often at a cost, especially in the elderly with the potential or reality of myocardial ischemia, pulmonary edema, or renal compromise.

\section{A new mechanism}

Recent reviews of cerebral vasospasm provide newer insights to the underlying mechanism of vasospasm. An exciting concept is that vasospasm is related to cortical spreading depression (SD). ${ }^{6,11-21}$ In Table 1, there is a synopsis of the current relevant literature based on a search in PubMed with the following strategy, "spreading depression" OR "cortical spreading depression" AND "subarachnoid hemorrhage". Nine of the 13 papers highlighted were published within the past two years. Over 60 years ago, Leão first described spreading depression in experimental animals as a wave of electroencephalogram (EEG) silence moving slowly across the cortical surface (typically at 2-4 $\mathrm{mm} \cdot \mathrm{min}^{-1}$ ). ${ }^{22,23}$ For the interested reader, a comprehensive review of spreading depression is given by G.G. Somjen. ${ }^{24}$ Much work in the 1970 s and 80 s identified the marked alterations in neuroglial ion fluxes that occurred with SD (extracellular potassium rapidly increasing to $40-50 \mathrm{meq} \cdot \mathrm{L}^{-1}$ resulting in EEG silence with
Fig. 1 A stylized diagram of the historical conception of subarachnoid blood leading to cerebral vasoconstriction. Local bleeding leads to heme breakdown products resulting in cerebral vasoconstriction with ischemic damage to adjacent neurons

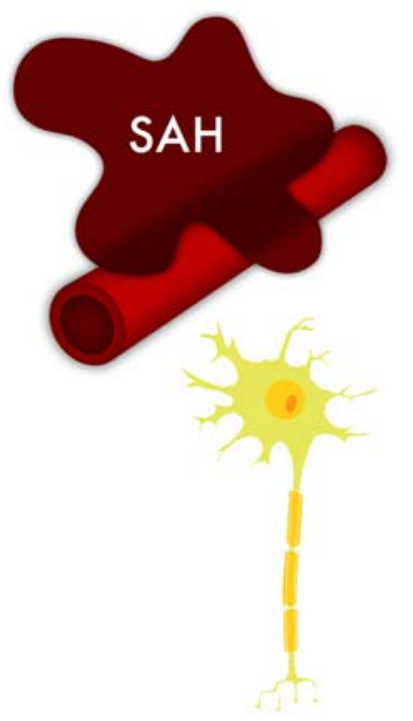

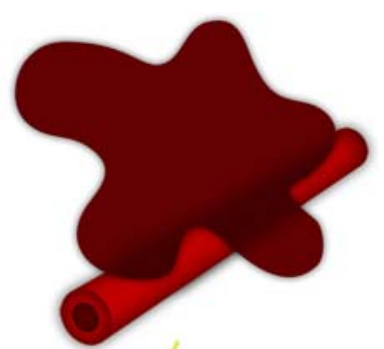

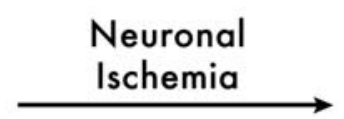




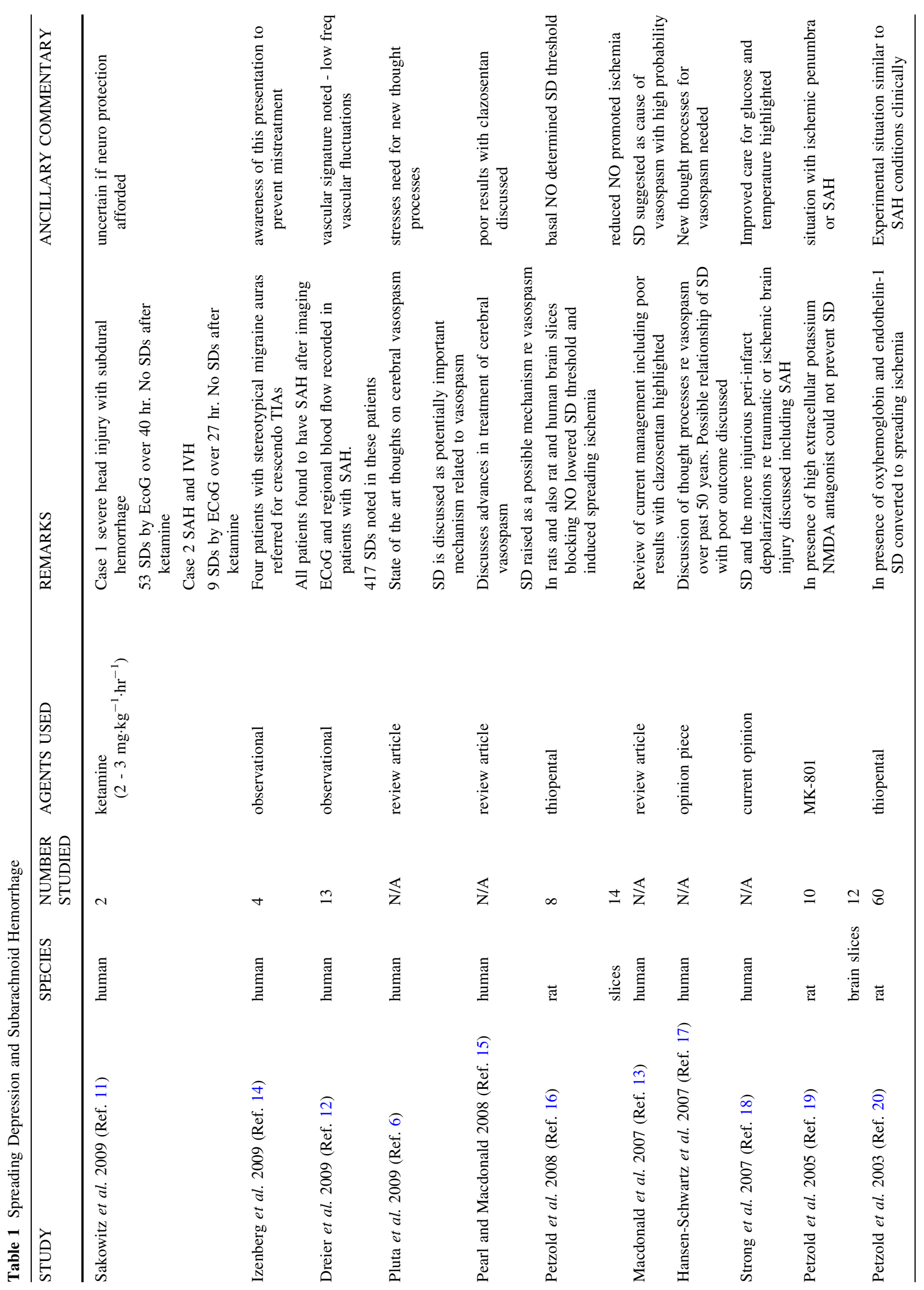


concomitant decrease in extracellular sodium, chloride, and calcium with a net decrease in extracellular volume at the wave front with movement of water into cells). There is marked hyperemia with the spreading wavefront, followed by a modest long-lasting regional oligemia after passage. ${ }^{24}$ Nedergaard and Hansen ${ }^{25}$ found no evidence of ischemic pathology in the cortex of rats with a normally perfused cortex. A considerable body of work has equated SD as the underlying mechanism of classical migraine (see review by Gorji). ${ }^{26}$ Now a series of studies have demonstrated that multiple SD waves can occur in patients following SAH. ${ }^{12,27}$

Following middle cerebral artery occlusion (MCAO) in the baboon, Branston et al. ${ }^{28}$ identified transient increases in extracellular potassium with voltage alterations similar to those seen with SD in the ischemic penumbra. Strong and Dardis ${ }^{29}$ provided further elucidation in cats. Such penumbral disturbances became known as peri-infarct depolarizations (PIDs). These PIDs differ from SDs in that they are spontaneous, of greater ion flux duration, and associated with protracted periods of ischemic blood flow. Progression to terminal depolarization can occur with repeated PIDs unless substrate delivery can be enhanced. It is suggested that PIDs increase the size of the umbral region of ischemia unless controlled. A very comprehensive overview of these events entitled Depolarization phenomena in traumatic and ischemic brain injury is provided by Strong and Dardis. ${ }^{29}$

Resolution of the extracellular potassium load following SD is primarily a function of astrocytes. ${ }^{30}$ The astrocyte behaves as a nearly perfect potassium electrode with local changes in membrane potential difference reflective of local potassium concentration. ${ }^{31}$ Astrocytic spatial buffering of local changes in potassium enables neuronal transmembrane potential to be re-established for subsequent discharge. The spatial buffering is accomplished through the astrocytes behaving as a synctium. Recent evidence indicates that this function is, in part, accomplished via connections through cellular hemichannels and gap junctions. ${ }^{32}$ Ischemia has been shown to open gap junction hemichannels in neurons providing a mechanism for the marked fluxes seen in ions. ${ }^{33}$ Intracellular recordings indicate that the neuronal transmembrane potential $\left(\mathrm{V}_{\mathrm{m}}\right)$ can reach zero millivolts $(\mathrm{mV})$ with $\mathrm{SD}$. This is different from that seen with neuronal discharge where $V_{m}$ reaches $+20 \mathrm{mV}$. It has been suggested that simultaneous opening of several or all membrane conductances occur with SD (energy dependent, voltage-gated, ionophoretic, and hemichannel). ${ }^{29}$

One of the hallmarks of SD is that a protracted period of decreased cerebral blood flow is seen following the event. ${ }^{34}$ Multiple SD waves can enhance this effect. ${ }^{35}$ The effect is greatly enhanced with the onset of peri-infarct 
depolarizations. ${ }^{18}$ Recurrent SD or PID waves result in local glutamate toxicity due to decreased clearance of glutamate load secondary to inadequate spatial buffering by astrocytes. Spreading depression increases the expression of inflammatory cytokines, such as interleukins (IL$1 \beta)$ and tumour necrosis factor- $\alpha^{36}$ In this context, microglia - the macrophages of the brain - release multiple cytotoxins further impairing astrocyte function. ${ }^{32}$ In contrast, microglia have also been shown to block the spread of local damage in the brain by process outgrowth that is chloride channel dependent. ${ }^{37}$ In the face of multiple SD or PID waves, it is uncertain if local damage control, as above, could become more generalized. The microglial cytotoxins attract inflammatory cells that contribute to the well-documented increase in inflammation of the cerebral vessels suffering from vasospasm. When SD is initiated experimentally, neuronal injury occurs with evidence of oxidative stress in the presence of astrocyte energy failure. $^{38}$ Spreading depression results in reactive oxygen species (ROS) production, in and of itself, independent of subarachnoid blood ${ }^{39,40}$ and also initiates expression of immediate early genes, such as c-fos and jun-B. ${ }^{41}$

Woertgen et al. $^{42}$ have shown the relationship between intraoperative clipping of cerebral aneurysms and the risk of cerebral vasospasm. In patients with temporary clipping of feeding vessels, the incidence of cerebral vasospasm was much higher than if a temporary clip was not required (34\% vs 20\%). As well, temporary clipping duration was correlated with the development of vasospasm. Prevention of cerebral hypoxia in the ipsilateral hemisphere during temporary clipping of the feeding vessel to the aneurysm appears paramount and may be an inciting mechanism for SD during surgery. Also, the rare but documented occurrence of cerebral vasospasm following successful clipping of an unruptured aneurysm can be explained by the SD model of cerebral vasospasm. ${ }^{43}$ Twenty-five years ago, Dr. Gardner-Medwin and the author suggested the importance of recurrent SD as a potential source of injury and poor outcome in neurosurgical patients. ${ }^{44}$ As well, these authors have studied the effect of hypocapnia (a standard of care during neurosurgical procedures to control intraoperative brain volume) on prolonged resolution of the extracellular potassium load if SD should occur. ${ }^{45}$

\section{Newer potential mechanisms for vessel narrowing}

Recent work provides a mechanism linking the presence of PIDs and the large vessel narrowing that is seen with established cerebral vasospasm. ${ }^{46}$ Cerebral ischemia and subsequent infarction with PIDs have been proposed as the underlying mechanism of widespread cortical infarction seen diffusely at autopsy following lethal SAH. Spreading ischemia or PID can be induced in rats with a topical application of oxyhemoglobin (as a NO scavenger) in the presence of elevated potassium concentration. ${ }^{47}$ In vitro experiments demonstrate that superfusing isolated middle cerebral arteries with an ionic cocktail with a composition similar to that seen following PIDs results in vessel constriction in the presence of NO synthase inhibition. The change in diameter from baseline conditions approached $50 \%$ narrowing. ${ }^{46}$ The predominant vasoconstrictor in the cocktail was the elevated concentration of potassium. Herein lies a mechanism relating the parenchymal alterations that are seen with PID with SAH and large conducting vessel constriction.

\section{Glial-centric model of vasospasm}

Collectively, the above analysis suggests that the lesion leading to cerebral vasospasm following subarachnoid bleeding is not principally an alteration in the cerebral vessel, as historically thought, but is a consequence of glial cell dysfunction - both astrocyte and microglia following SD transitioning to PID (Figure 2). Noxious stimuli (represented by blood and its breakdown products) initiate the SD or PID waves. The astrocyte is unique in providing a support function to neurons. Each astrocyte foot process on a cerebral vessel provides a critical linkage between neuron and vessel. Astrocytes behaving as a synctium are critical to spatially buffer extracellular potassium (re-establishing the transmembrane potential to permit neuronal function) and to spatially buffer glutamate (a neurotransmitter that can quickly become neurotoxic). ${ }^{32}$ Astrocytes control local vasomotor tone via direct contact with the cerebral vasculature. Recent work indicates that elevated intracellular calcium in astrocytic endfeet, a recognized consequence of neuroglial ion fluxes seen with SD, results in local cerebral vasoconstriction following production of 20-HETE in vascular smooth muscle in an environment of low concentrations of NO. ${ }^{48}$ As noted above, this exact scenario exists with SAH with high levels of 20-HETE and consumption of NO from heme breakdown products. ${ }^{49}$ The spatial buffering of the astrocyte with generated intracellular calcium waves ${ }^{50}$ is a clue as to why vasospasm can become generalized, even in the face of local cisternal blood following rupture of a cerebral vessel. The above alterations in astrocyte signalling and microenvironment changes provide a mechanism to understand the origin of marked local oligemia with PID. The author, together with Gardner-Medwin, have shown the effects of diminished substrate supply to the recovery of SD waves by initiating hypocapnia either with or without mild changes in perfusion pressure. $^{51}$ Also, the author highlighted the mechanisms of extracellular acidosis by SD and its 
Fig. 2 A stylized diagram of the glial-centric model of cerebral vasospasm following the formation of spreading depression (SD) waves. Blood in the subarachnoid space generates multiple SD waves that cause glial cell dysfunction following glutamate accumulation with hemichannel disruption. Local glutamate toxicity results in the release of inflammatory cytokines from microglia. Spreading depression waves result in increased intracellular calcium concentrations in astrocytic endfeet generating 20-HETE with smooth muscle contraction in the cerebral vessel, which leads to vasoconstriction and neuronal ischemic damage

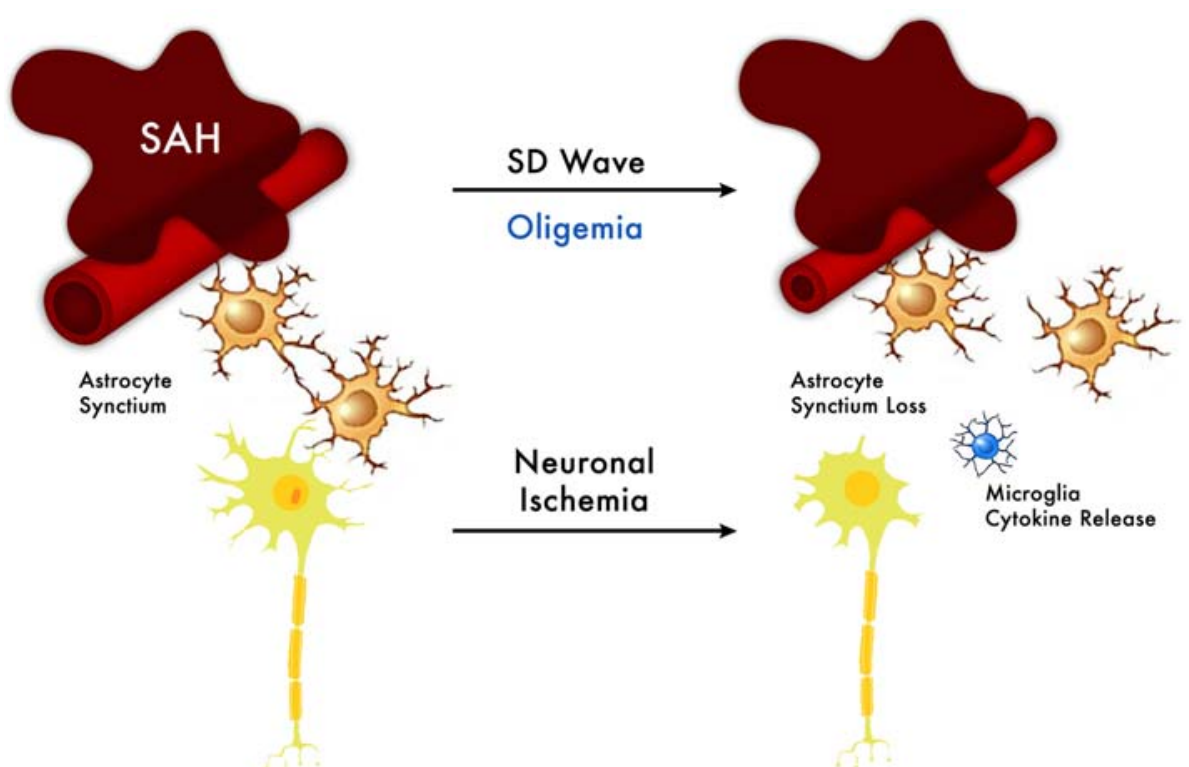

similarities to cerebral ischemia. ${ }^{52}$ Extracellular acidosis can lead to permanent closure of hemichannels leading to local astrocyte dysfunction. ${ }^{53,54}$ Non-vesicular glutamate release can be modulated by alterations in $\mathrm{pH}^{55}$ With glutamate toxicity, microglia become activated and release cytotoxins via hemichannels. ${ }^{56}$

\section{Consequences of the glial-centric model of cerebral vasospasm}

The described mechanisms to account for cerebral vasospasm based on glial cells rather than endothelial cells provide insight into our lack of progress in the treatment of vasospasm. Despite numerous improvements in neurosurgery, neuroanesthesia, critical care, and interventional radiology, the harsh reality is that advances in the management of cerebral vasospasm have been, at best, incremental. Cerebral angioplasty is a recognized advance in the management of cerebral vasospasm, but this is a mechanical intervention not furthering our understanding of the inciting mechanisms. Various vasodilators and antiinflammatory agents have been tried with very limited success. Nimodipine is the only vasodilator that is widely used. ${ }^{57}$ Real hope was placed on the introduction of clazosentan (a specific endothelin-1 antagonist), but despite evidence of attenuation of vessel spasm, outcome was not improved and a number of complications may have contributed to the lack of success, including pulmonary complications and systemic hypotension. ${ }^{15}$ Such disappointment with an agent expected to be very successful strongly suggests that a true understanding of what vasospasm comprises remains elusive. A glial-centric theory that accounts for cerebral vasospasm bears a resemblance to a recently published thesis that astrocyte dysfunction is pivotal to Wernicke's encephalopathy with thiamine deficiency. ${ }^{58}$

\section{Potential consequences of a glial-centric model of vasospasm}

If a glial-centric model of cerebral vasospasm is correct, a number of our standard therapies are problematic. Anesthetic agents may be especially important in this context. Table 2 highlights the retrieved studies examining the impact of anesthetic agents on spreading depression. This is a synopsis of the current relevant literature based on a search in PubMed with the following strategy, "spreading depression" OR "cortical spreading depression" AND "anesthetic agents". Seventy-eight papers were identified, and the 15 that were documented involve a comparison of various anesthetic agents or deal with an anesthetic agent compared with awake controls on SD propagation and were published in the last 20 years. ${ }^{59-73}$ The majority of these studies compared volatile agents primarily with $\alpha$-chloralose. Halothane consistently attenuates SD waves. Less information is available for isoflurane and sevoflurane. No data are available for desflurane. Ketamine, a known Nmethyl D-aspartate (NMDA) receptor antagonist, is a potent attenuator of SD waves. Fixed agents, such as thiopental, pentobarbitone, diazepam, $\alpha$-chloralose, and equithesin are markedly less efficacious. It is worth noting that propofol has not been studied but would be expected to be similar to the other fixed agents. In light of the data from Table 2, the following commentary is advanced: 


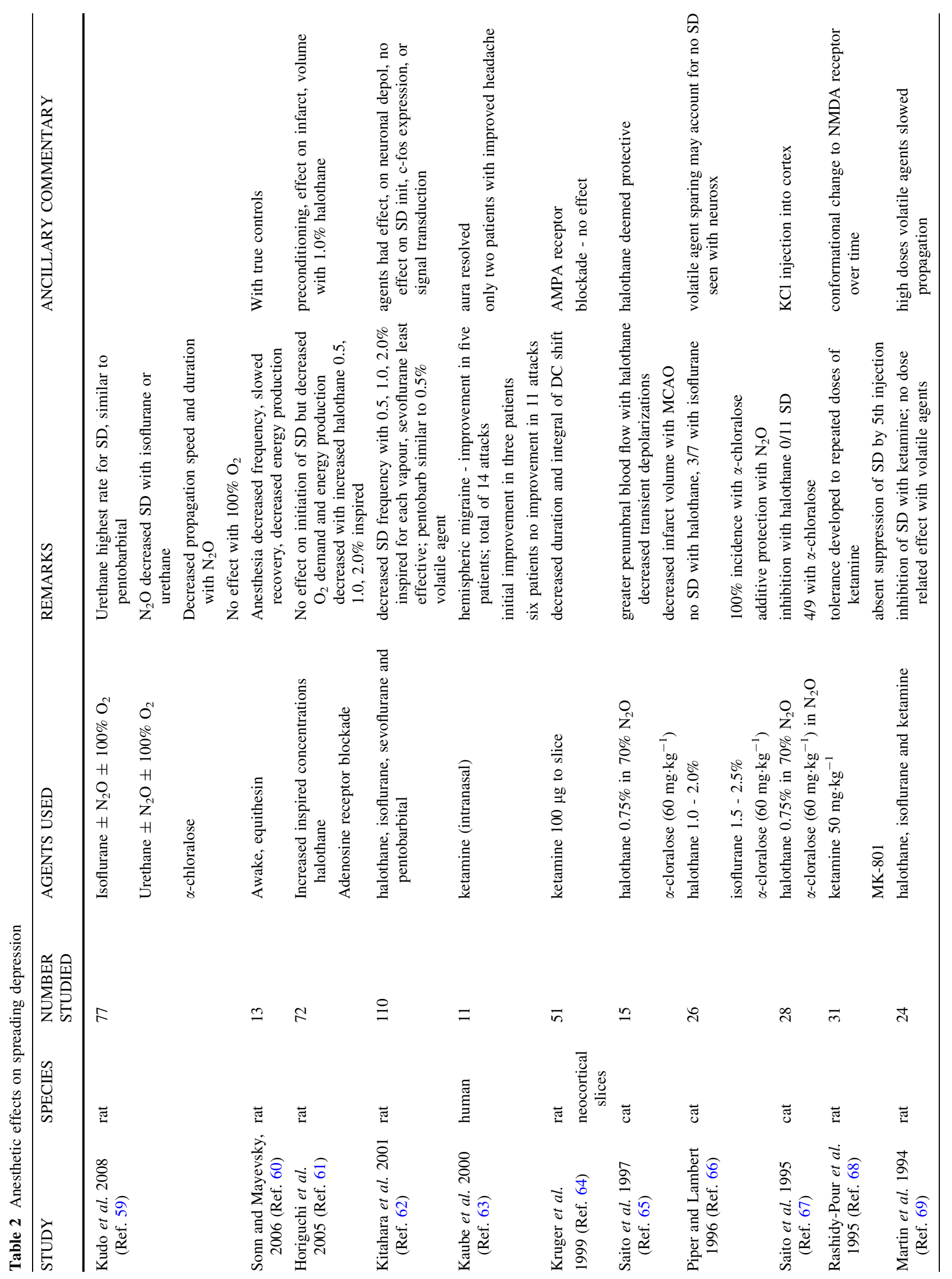


The use of propofol (a common approach to sedation in the intensive care unit) may well be contraindicated in the management of sedation for patients with severe vasospasm. Evidence that propofol attenuates hemichannel communication is potentially of considerable importance. ${ }^{74}$ Thus, by its actions on hemichannels, propofol can prevent spatial buffering of potassium and glutamate and enhance the risk of SD or the risk of multiple SD waves or PIDs. Volatile agents and, most specifically, isoflurane have a significantly smaller effect on gap junction function than that seen with propofol. Isoflurane is a cerebral vasodilator, whereas propofol is a cerebral vasoconstrictor based on reduction in metabolic demand. In the context of fully monitored patients with severe vasospasm, use of a cerebral vasodilator can be rationally entertained. By using a volatile agent for sedation, it is possible that less vigorous "triple-H" therapy would be required with extra-organ complications attenuated. As volatile agents decrease the risk of generating SD waves, the mere change of the approach to sedation could improve outcome following severe vasospasm. The use of volatile agents in an intensive care setting is logistically problematic, but approaches have been developed, including the introduction of a volatile anesthetic reflection filter that is adaptable to conventional intensive care ventilators - the so-called AnaConDa (anesthetic conserving device). ${ }^{75}$ Another risk of using propofol for sedation in the neurocritical care setting is the propofol infusion syndrome - potential for metabolic, cardiac, renal, and hepatic dysfunction and rhabdomyolysis with high doses and/or prolonged infusion of the agent. Recent work suggests that patients with neurologic disorders may be at greater risk - a 35\% incidence of the infusion syndrome in patients managed with refractory epilepsy ${ }^{76}$ vs a $3.7 \%$ incidence in general intensive care unit patients. ${ }^{77}$

Ketamine should be studied for sedation in patients with severe vasospasm. Recent work has again confirmed the potential utility of this NMDA antagonist in diminishing the frequency of SD. ${ }^{11}$ In the observational study by Dreier et al., ${ }^{12}$ ketamine was used as a rescue agent in the presence of documented SD or PID waves in monitored patients. Prophylactic administration should be considered in patients at risk. Another agent known to attenuate SD incidence is octanol. ${ }^{36}$ This agent has been used in lower animals but not clinically.

The agent chosen to augment perfusion pressure in "triple-H" therapy bears investigation in relation to this glialcentric model. Phenylephrine or other $\alpha$-agonists may not be the optimal choice to augment perfusion pressure, as $\alpha$-receptor binding increases astrocyte calcium, causes contraction of cerebrovascular smooth muscle, and activates vascular pericytes ${ }^{78}$ that cause local vasoconstriction. ${ }^{48}$ Dopamine has recently been shown to attenuate cerebral 
vasospasm in an in-vitro model, ${ }^{79}$ and further study into its effects on astrocyte calcium flux may be warranted.

\section{Conclusions}

Clearly, much bench-top investigation and clinical work would be required to support or refute the claims advanced here regarding a glial-centric origin of cerebral vasospasm. Focusing on the prevention of spreading depression waves or peri-infarct depolarizations to limit glial cell dysfunction would be a sea change in the clinical management of $\mathrm{SAH}$ and cerebral vasospasm. This perspective provides further evidence of the importance of astrocytes to the neurovascular interface.

Funding Academic Oversight Committee, Department of Anesthesia, University of Manitoba.

Conflicts of interest None declared.

\section{References}

1. Komotar RJ, Schmidt JM, Starke RM, et al. Resuscitation and critical care of poor-grade subarachnoid hemorrhage. Neurosurgery 2009; 64: 397-410.

2. Smith $M$. Intensive care management of patients with subarachnoid haemorrhage. Curr Opin Anaesthesiol 2007; 20: 400-7.

3. Crowley $R W$, Medel R, Kassell NF, Dumont AS. New insights into the causes and therapy of cerebral vasospasm following subarachnoid hemorrhage. Drug Discov Today 2008; 13: 254-60.

4. Keyrouz SG, Diringer MN. Clinical review: Prevention and therapy of vasospasm in subarachnoid hemorrhage. Crit Care 2007; 11: 220.

5. Pyne-Geithman GJ, Caudell DN, Prakash P, Clark JF. Glutathione peroxidase and subarachnoid hemorrhage: implications for the role of oxidative stress in cerebral vasospasm. Neurol Res 2009; 31: 195-9.

6. Pluta RM, Hansen-Schwartz J, Dreier J, et al. Cerebral vasospasm following subarachnoid hemorrhage: time for a new world of thought. Neurol Res 2009; 31: 151-8.

7. Andresen J, Shafi NI, Bryan RM Jr. Endothelial influences on cerebrovascular tone. J Appl Physiol 2006; 100: 318-27.

8. Kolias AG, Sen J, Belli A. Pathogenesis of cerebral vasospasm following aneurysmal subarachnoid hemorrhage: putative mechanisms and novel approaches. J Neurosci Res 2009; 87: 1-11.

9. Lee KH, Lukovits T, Friedman JA. "Triple-H" therapy for cerebral vasospasm following subarachnoid hemorrhage. Neurocrit Care 2006; 4: 68-76.

10. Muench E, Horn P, Bauhuf, et al. Effects of hypervolemia and hypertension on regional cerebral blood flow, intracranial pressure, and brain tissue oxygenation after subarachnoid hemorrhage. Crit Care Med 2007; 35: 1844-51.

11. Sakowitz $O W$, Kiening KL, Krajewski KL, et al. Preliminary evidence that ketamine inhibits spreading depolarizations in acute human brain injury. Stroke 2009; 40: e519-22.

12. Dreier JP, Major S, Manning A, et al. Cortical spreading ischaemia is a novel process involved in ischaemic damage in patients with aneurysmal subarachnoid haemorrhage. Brain 2009; 132: $1866-81$.

13. Macdonald RL, Pluta RM, Zhang JH. Cerebral vasospasm after subarachnoid hemorrhage: the emerging revolution. Nat Clin Pract Neurol 2007; 3: 256-63.

14. Izenberg A, Aviv RI, Demaerschalk BM, et al. Crescendo transient aura attacks: a transient ischemic attack mimic caused by focal subarachnoid hemorrhage. Stroke 2009; 40: 3725-9.

15. Pearl JD, Macdonald RL. Vasospasm after aneurysmal subarachnoid hemorrhage: need for further study. Acta Neurochir Suppl 2008; 105: 207-10.

16. Petzold GC, Haack S, von Bohlen Und Halbach O, et al. Nitric oxide modulates spreading depolarization threshold in the human and rodent cortex. Stroke 2008; 39: 1292-9.

17. Hansen-Schwartz J, Vajkoczy P, Macdonald RL, Pluta RM, Zhang JH. Cerebral vasospasm: looking beyond vasoconstriction. Trends Pharmacol Sci 2007; 28: 252-6.

18. Strong AJ, Anderson PJ, Watts HR, et al. Peri-infarct depolarizations lead to loss of perfusion in ischaemic gyrencephalic cerebral cortex. Brain 2007; 130: 995-1008.

19. Petzold GC, Windmuller $O$, Haack $S$, et al. Increased extracellular $\mathrm{K}^{+}$concentration reduces the efficacy of N-methyl-Daspartate receptor antagonists to block spreading depression-like depolarizations and spreading ischemia. Stroke 2005; 36: 1270-7.

20. Petzold GC, Einhaupl KM, Dirnagl U, Dreier JP. Ischemia triggered by spreading neuronal activation is induced by endothelin- 1 and hemoglobin in the subarachnoid space. Ann Neurol 2003; 54: 591-8.

21. van den Bergh WM, Zuur JK, Kamerling NA, et al. Role of magnesium in the reduction of ischemic depolarization and lesion volume after experimental subarachnoid hemorrhage. J Neurosurg 2002; 97: 416-22.

22. Leao AA. Spreading depression of activity in the cerebral cortex. J Neurophysiol 1944; 7: 359-90.

23. Leao AA. Further observations on the spreading depression of activity in the cerebral cortex. J Neurophysiol 1947; 10: 409-14.

24. Somjen GG. Mechanisms of spreading depression and hypoxic spreading depression-like depolarization. Physiol Rev 2001; 81: 1065-96.

25. Nedergaard $M$, Hansen AJ. Spreading depression is not associated with neuronal injury in the normal brain. Brain Res 1988; 449: 395-8.

26. Gorji A. Spreading depression: a review of the clinical relevance. Brain Res Brain Res Rev 2001; 38: 33-60.

27. Dreier JP, Woitzik J, Fabricius M, et al. Delayed ischaemic neurological deficits after subarachnoid haemorrhage are associated with clusters of spreading depolarizations. Brain 2006; 129: 3224-37.

28. Branston NM, Strong AJ, Symon L. Extracellular potassium activity, evoked potential and tissue blood flow. Relationships during progressive ischaemia in baboon cerebral cortex. J Neurol Sci 1977; 32: 305-21.

29. Strong AJ, Dardis R. Depolarisation phenomena in traumatic and ischaemic brain injury. Adv Tech Stand Neurosurg 2005; 30: 349.

30. Gardner-Medwin AR. A study of the mechanisms by which potassium moves through brain tissue in the rat. J Physiol 1983; 335: 353-74.

31. Gardner-Medwin AR. Analysis of potassium dynamics in mammalian brain tissue. J Physiol 1983; 335: 393-426.

32. Orellana JA, Saez PJ, Shoji KF, et al. Modulation of brain hemichannels and gap junction channels by pro-inflammatory agents and their possible role in neurodegeneration. Antioxid Redox Signal 2009; 11: 369-99.

33. Thompson RJ, Zhou N, MacVicar BA. Ischemia opens neuronal gap junction hemichannels. Science 2006; 312: 924-7. 
34. Piilgaard H, Lauritzen M. Persistent increase in oxygen consumption and impaired neurovascular coupling after spreading depression in rat neocortex. J Cereb Blood Flow Metab 2009; 29: 1517-27.

35. Rawanduzy A, Hansen A, Hansen TW, Nedergaard M. Effective reduction of infarct volume by gap junction blockade in a rodent model of stroke. J Neurosurg 1997; 87: 916-20.

36. Jander S, Schroeter M, Peters O, Witte OW, Stoll G. Cortical spreading depression induces proinflammatory cytokine gene expression in the rat brain. J Cereb Blood Flow Metab 2001; 21: 218-25.

37. Hines DJ, Hines RM, Mulligan SJ, MacVicar BA. Microglia processes block the spread of damage in the brain and require functional chloride channels. Glia 2009; 57: 1610-8.

38. Lian $X Y$, Stringer $J L$. Energy failure in astrocytes increases the vulnerability of neurons to spreading depression. Eur J Neurosci 2004; 19: 2446-54.

39. Kraig RP, Dong LM, Thisted R, Jaeger CB. Spreading depression increases immunohistochemical staining of glial fibrillary acidic protein. J Neurosci 1991; 11: 2187-98.

40. Netto M, Do Carmo RJ, Martins-Ferreira H. Retinal spreading depression induced by photoactivation: involvement of free radicals and potassium. Brain Res 1999; 827: 221-4.

41. Sharp FR, Lu A, Tang Y, Millhorn DE. Multiple molecular penumbras after focal cerebral ischemia. J Cereb Blood Flow Metab 2000; 20: 1011-32.

42. Woertgen C, Rothoerl RD, Albert R, Schebesch KM, Ullrich OW. Effects of temporary clipping during aneurysm surgery. Neurol Res 2008; 30: 542-6.

43. Paolini S, Kanaan Y, Wagenbach A, Fraser K, Lanzino G. Cerebral vasospasm in patients with unruptured intracranial aneurysms. Acta Neurochir (Wien) 2005; 147: 1181-8.

44. Gardner-Medwin AR, Mutch WAC. Experiments on spreading depression in relation to migraine and neurosurgery. An Acad Bras Cienc 1984; 56: 423-30.

45. Takano T, Tian GF, Peng $W$, et al. Cortical spreading depression causes and coincides with tissue hypoxia. Nat Neurosci 2007; 10: 754-62.

46. Windmuller $O$, Lindauer $U$, Foddis $M$, et al. Ion changes in spreading ischaemia induce rat middle cerebral artery constriction in the absence of NO. Brain 2005; 128: 2042-51.

47. Dreier JP, Korner K, Ebert $N$, et al. Nitric oxide scavenging by hemoglobin or nitric oxide synthase inhibition by N-nitro-Larginine induces cortical spreading ischemia when $\mathrm{K}^{+}$is increased in the subarachnoid space. J Cereb Blood Flow Metab 1998; 18: 978-90.

48. Mulligan SJ, MacVicar BA. Calcium transients in astrocyte endfeet cause cerebrovascular constrictions. Nature 2004; 431: 195-9.

49. Koehler RC, Gebremedhin D, Harder DR. Role of astrocytes in cerebrovascular regulation. J Appl Physiol 2006; 100: 307-17.

50. Verkhratsky A. Glial calcium signaling in physiology and pathophysiology. Acta Pharmacol Sin 2006; 27: 773-80.

51. Mutch WAC, Gardner-Medwin AR. The influence of hypocarbia on the resolution of transient increases in brain extracellular potassium. Anesthesiology 1987; 66: 350-5.

52. Mutch WAC, Hansen AJ. Extracellular $\mathrm{pH}$ changes during spreading depression and cerebral ischemia: mechanisms of brain pH regulation. J Cereb Blood Flow Metab 1984; 4: 17-27.

53. Saez JC, Contreras JE, Bukauskas FF, Retamal MA, Bennett MV. Gap junction hemichannels in astrocytes of the CNS. Acta Physiol Scand 2003; 179: 9-22.

54. Trexler EB, Bukauskas FF, Bennett MV, Bargiello TA, Verselis $V K$. Rapid and direct effects of $\mathrm{pH}$ on connexins revealed by the connexin46 hemichannel preparation. J Gen Physiol 1999; 113: 721-42.
55. Billups B, Attwell D. Modulation of non-vesicular glutamate release by $\mathrm{pH}$. Nature $1996 ; 379$ : 171-4.

56. Figiel M, Allritz C, Lehmann C, Engele J. Gap junctional control of glial glutamate transporter expression. Mol Cell Neurosci 2007; 35: 130-7.

57. Tomassoni D, Lanari A, Silvestrelli G, Traini E, Amenta F. Nimodipine and its use in cerebrovascular disease: evidence from recent preclinical and controlled clinical studies. Clin Exp Hypertens 2008; 30: 744-66.

58. Hazell AS, Rao KV, Danbolt NC, Pow DV, Butterworth RF. Selective down-regulation of the astrocyte glutamate transporters GLT-1 and GLAST within the medial thalamus in experimental Wernicke's encephalopathy. J Neurochem 2001; 78: 560-8.

59. Kudo C, Nozari A, Moskowitz MA, Ayata C. The impact of anesthetics and hyperoxia on cortical spreading depression. Exp Neurol 2008; 212: 201-6.

60. Sonn J, Mayevsky A. Effects of anesthesia on the responses to cortical spreading depression in the rat brain in vivo. Neurol Res 2006; 28: 206-19.

61. Horiguchi T, Kis B, Rajapakse N, Shimizu K, Busija DW. Cortical spreading depression (CSD)-induced tolerance to transient focal cerebral ischemia in halothane anesthetized rats is affected by anesthetic level but not ATP-sensitive potassium channels. Brain Res 2005; 1062: 127-33.

62. Kitahara $Y$, Taga $K$, Abe H, Shimoji $K$. The effects of anesthetics on cortical spreading depression elicitation and c-fos expression in rats. J Neurosurg Anesthesiol 2001; 13: 26-32.

63. Kaube H, Herzog J, Kaufer T, Dichgans M, Diener HC. Aura in some patients with familial hemiplegic migraine can be stopped by intranasal ketamine. Neurology 2000; 55: 139-41.

64. Kruger H, Heinemann U, Luhmann HJ. Effects of ionotropic glutamate receptor blockade and 5-HT1A receptor activation on spreading depression in rat neocortical slices. Neuroreport 1999; 10: 2651-6.

65. Saito R, Graf R, Hubel K, Fujita T, Rosner G, Heiss WD. Reduction of infarct volume by halothane: effect on cerebral blood flow or perifocal spreading depression-like depolarizations. J Cereb Blood Flow Metab 1997; 17: 857-64.

66. Piper RD, Lambert GA. Inhalational anesthetics inhibit spreading depression: relevance to migraine. Cephalalgia 1996; 16: 87-92.

67. Saito R, Graf R, Hubel K, et al. Halothane, but not alpha-chloralose, blocks potassium-evoked cortical spreading depression in cats. Brain Res 1995; 699: 109-15.

68. Rashidy-Pour A, Motaghed-Larijani Z, Bures J. Tolerance to ketamine-induced blockade of cortical spreading depression transfers to MK-801 but not to AP5 in rats. Brain Res 1995; 693: 64-9.

69. Martin H, Warner DS, Todd MM. Effects of glycine receptor antagonism on spreading depression in the rat. Neurosci Lett 1994; 180: 285-9.

70. Verhaegen $M$, Todd $M$, Warner D. A comparison of cerebral ischemic flow thresholds during halothane/nitrous oxide and isoflurane/nitrous oxide anesthesia in rats. Anesthesiology 1992; 76: 743-54.

71. Guedes RC, Barreto JM. Effect of anesthesia on the propagation of cortical spreading depression in rats. Braz J Med Biol Res 1992; 25: 393-7.

72. Amemori T, Bures $J$. Ketamine blockade of spreading depression: rapid development of tolerance. Brain Res 1990; 519: 351-4.

73. Marrannes R, Willems $R$, De Prins $E$, Wauquier A. Evidence for a role of the N-methyl-D-aspartate (NMDA) receptor in cortical spreading depression in the rat. Brain Res 1988; 457: 226-40.

74. Wentlandt K, Samoilova M, Carlen PL, El Beheiry H. General anesthetics inhibit gap junction communication in cultured organotypic hippocampal slices. Anesth Analg 2006; 102: 1692-8. 
75. Meiser A, Laubenthal $H$. Inhalational anaesthetics in the ICU: theory and practice of inhalational sedation in the ICU, economics, risk-benefit. Best Pract Res Clin Anaesthesiol 2005; 19: 523-8.

76. Iyer VN, Hoel R, Rabinstein AA. Propofol infusion syndrome in patients with refractory status epilepticus: an 11-year clinical experience. Crit Care Med 2009; 37: 3024-30.

77. Roberts $R$, Devlin JW, Schumaker G. Incidence of propofol infusion in critically ill adults. Crit Care Med 2008; 36: A180. abstract.
78. Peppiatt CM, Howarth C, Mobbs P, Attwell D. Bidirectional control of CNS capillary diameter by pericytes. Nature 2006; 443: 700-4.

79. Pyne-Geithman GJ, Caudell DN, Cooper M, Clark JF, Shutter $L A$. Dopamine D2-receptor-mediated increase in vascular and endothelial NOS activity ameliorates cerebral vasospasm after subarachnoid hemorrhage in vitro. Neurocrit Care 2009; 10: 22531. 